\title{
Energy-Efficiency Concept for the Manufacturing Industry
}

\author{
Volker Stich, Niklas Hering, Christian Paul Starick, and Ulrich Brandenburg \\ Institute for Industrial Management at RWTH Aachen University, Pontdriesch 14/16, \\ 52062 Aachen, Germany \\ \{Volker.Stich, Niklas.Hering, Christian.Starick, \\ Ulrich.Brandenburg\} efir.rwth-aachen. de
}

\begin{abstract}
Depletion of fossil energy sources, rising energy prices and government regulation coerces manufacturing companies to foster their energyefficiency. Among others, Information and communication technologies (ICT) are considered to be major enablers for improving the energy-efficiency. In this paper a concept for energy-efficiency based on an Event-driven Architecture (EDA) using Complex-Event-Processing (CEP) is presented that supports the integration of sensor data from the shop-floor level into the company's decision support systems. Finally, a use-case for implementing the proposed concept in a real production environment is presented.
\end{abstract}

Keywords: Energy-Efficiency, Real-Time Capability, Event-driven Architecture, Complex Event Processing, Production Planning and Scheduling.

\section{$1 \quad$ Introduction}

The so-called "energy concept 2050" of the German Federal Government calls for a complete change of the German energy supply. The ambition is to establish one of the most sustainable and energy-efficient economies. By the year 2020 the proportion of renewable energy sources such as wind, solar and water power should account for up to $35 \%$ of the German energy mix [1]. The manufacturing industry is one of the biggest consumers of primary energy $(31 \%)$ and one of the largest emitters of $\mathrm{CO}_{2}$ [2]. Although energy intensity has declined within the European Union over the last 30 years there is still an unrealized long-term energy efficiency economical potential in the industry sector of almost 60 per cent [3]. Among others, Information and Communication Technologies (ICT) play an important role for measurement, control and improvement of energy efficiency in manufacturing [4], [5]. ICT that is relevant for energy efficiency include Supervisory Control And Data Acquisition Systems (SCADA), Manufacturing Execution Systems (MES), Energy Management Systems (EMS) and Enterprise Resource Planning (ERP) Systems. However, the problem in manufacturing companies is how to use ICT and seamlessly integrate it into their production system. 
The EU research project "Sense\&React" aims at providing support for manufacturing companies to implement an ICT-infrastructure that feeds decision support systems to increase energy-efficiency. Therefore, role-specific aggregated information from various sources is provided to employees in manufacturing environments using a factory wide sensing and ICT end-to-end infrastructure. Among other things, a realtime optimisation method for energy efficiency shall be developed. [6]

In this paper, a detailed energy efficiency concept is presented. It acts as a conceptual framework that will support companies to analyse their production state regarding energy efficiency, providing them with detailed information about deviations from their targets (e.g. energy plan), and provide information regarding energy efficiency for production planning and control.

\section{State-of-the-Art: Real-Time Capable Information Integration for Supporting Energy Efficiency in the Manufacturing Industry}

As a first rough definition energy-efficiency can be expressed as the ratio between the useful output of a process and the energy input into a process [7]. The term energy efficiency is closely related to the term of energy productivity. Reinhart et al. define an increase in energy productivity as producing the same amount of products in the right time, with the right quality consuming less energy [8]. For companies of the manufacturing industry consuming less energy always means to reduce costs. Basically energy costs for manufacturing companies comprise of two components [9]:

- Basic energy price: Based on the total amount of energy consumed and measured in kilowatt-hours.

- Price for peak demand (price per kilowatt): Calculated based on the monthly (sometimes yearly) highest peak demand.

Therefore, in order to reduce energy costs and increase energy-efficiency, companies need a profound knowledge about their energy consumption in real-time. To realize the compliance of hard time constraints in technical processes, so called 'real-time systems' define today's information processing. Fleisch et al. [10] refer to a further development of production and logistics, containing ubiquitous computing and information systems. The 'Internet of Things' is a concrete approach for the realization of decentralized and completely integrated data handling [10]. To enable an autonomous data exchange between goods among themselves and with their environment, embedded systems are combined with Radio Frequency Identification (RFID) and sensor technology [10]. Within defined ranges, so called 'smart players' as self-contained and communication capable objects are able to make decisions and initiate activities independently [11]. This leads to a decentralization of the control of the material flow and to a need of low communication depth. The Electronic Product Code (EPC) and its related information services (EPCIS) are part of the implementation of the 'Internet of Things' [11]. 
Another important factor in providing information about production processes is sensing technology. Its significant developments as well as communication technology have become a relevant part in production systems. Whereas to today the use of wireless technology has mainly been limited to production monitoring and production system performance measurement applications [12] now a new generation of sensors is prevailing. Its characteristics are embeddable size devices, the possibility of wireless and untethered mode of operation, so called smart items and the Wireless Sensor Networks (WSNs). These networks are much acclaimed for many purposes and will be used in a variety of contexts [13]. Because of the demanding industrial requirements, security reasons and high degree of availability the integration of wireless IT technologies at shop floor level is often impeded [14], but by multi-channel communication interferences can be alleviated. With it parallel transmissions over different channels are enabled and the network throughput is improved [13]. To gain real-time visibility and traceability at the shop-floor level RFID technologies offer the capability of automatic and accurate object data capturing [15]. Therefore the management of the shop-floor and also the management of work-in-progress (WIP) can continuously be improved [16]. To master the challenge of the authentication management procedure a shared key between entities is needed. As one solution, a common key between two nodes can be generated which uses the secret key of one node and the identity of the other [17]. Also considerable is an innovation called push technology which can be a big support for shop-floor monitoring and training. The software client gets necessary information automatically without manual searching in data lists [18]. Moreover, mobile asset tracking and indoors localization sensing technologies have become popular. Their ranges of application are workforce productivity analysis, workforce training and safety monitoring. For outdoor environments and personnel tracking e. g. movable video camera systems have been proposed and pointed out the constraints when using vision-based tracking systems such as visual clutter or occluding and moving obstacles [19]. As analyses on human based assembly systems have shown, human operators are contemplated as major flexibility enablers because of their ability to react directly with changing products and market situations [20]. Hence it must be a key objective to integrate the human workers flexibly in the process, create the right conditions for them and allow them to perform different tasks. Bar code identification has been a proven, low cost and reliable technology and is extensively used for a long time now. But Radio Frequency Identification technology could prevail over the last decades because of the barcode's visual contact requirement and its inability of real time updates and of tracking single items [21].

\section{Approach for an Energy-Efficiency Concept for the Discrete Manufacturing Industry}

In order to use ICT and sensor networks (and therefore improve energy-efficiency) the concept of event-driven architectures (EDA) has gained acceptance as a new architectural paradigm for dealing with event streams produced by continuously data-emitting sensor networks [22], [23], [24]. Each event therefore contains general 
metadata (event ID, event-timestamp, event type, event occurrence number), and event-specific information such as sensor ID and data [25]. Due to the steadily increasing amount of available data it is necessary to detect patterns within a cloud of data. Complex event processing (CEP) is an event processing model introduced by Luckham [26] that can be used to identify those patterns of events that are significant for the application domain [22].

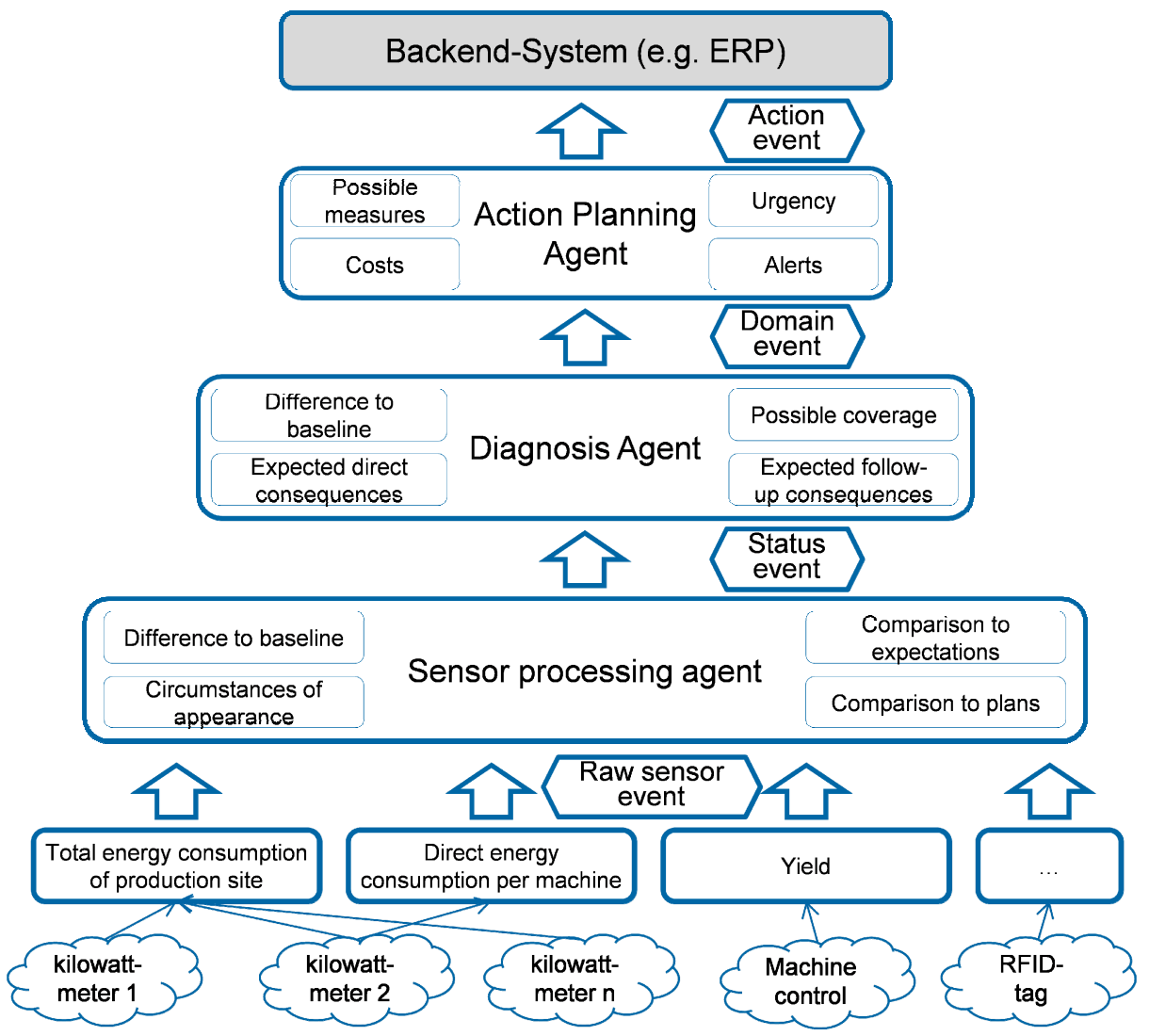

Fig. 1. Structural event model using CEP for energy-efficiency adapted from [22]

Fig. 1 illustrates the structural event model that is used for implementing the energy-efficiency concept in the manufacturing industry. It comprises of four hierarchical layered event types significant for the production environment [22]:

- Raw Sensor Events: Data collected from shop-floor sensor devices such as kilowatt-meters, machine-controls, or RFID tags attached to loading equipment. Problems often occur due to technical difficulties such as unreliable readings so the data has to be cleaned and pre-processed. Examples for raw sensor events are load curves of machines.

- Domain Events: In a next step the cleaned data has to be mapped to domain concepts. In a production system the load curves of the 
individual machines (Raw sensor event) can be synthesized to an overall load curve of the production system. Therefore, in this context examples of domain concepts are production events characterized by total energy consumption or work-in-progress.

- Status Events: Within this diagnosis step the domain events are synthesized to status events. Therewith, the overall state of the physical environment can be monitored. By comparison to an energy consumption baseline critical deviations can be identified.

- Action Events: Based on the status event certain action have to be derived. Within Sense\&React this action step will be an alert for the production line manager who might perform certain tasks to solve the problem.

Within the Sense\&React project this concept will be applied to a case-study for a factory-wide energy efficient production. The aim is to enable decentralized replanning on workstation level and to realize centralized monitoring and controlling concerning energy efficiency on management level (e. g. energy controller). The result will be to provide a power management system, which allows enabling, document and optimizing constantly an efficient use of energy. This can reduce energy costs and at the same time climate critical exhaust emissions. The application of the concept for the case-study will be explained in the following section.

\section{Manufacturing Use-Case: Energy-Efficient Production Sequencing}

For a production environment this concept can be implemented as following. Firstly, raw data from the shop-floor sensors such as kilowatt-meters, machine controls, RFID readers etc. is collected and raw sensor events are created. The Sensor Processing Agent cleans the raw sensor events ${ }^{1}$ and maps them to domain events such as load curves consisting of total energy consumption and peak loads. In the next step, the Diagnosis Agent executes continuous queries on the stream of domain events to derive status events. Status events can be derived by comparing a domain event such as the total load curve against the energy baseline taken from the database of the ERPsystem. Then, an action alert is created in this case an Alert Event containing a visualization of the detected deviation from the energy plan. A context-sensitive distribution of the Alert Event to a production line manager is also part of the Sense\&React Integrated System illustrated by Fig. 2. The production line manager then manipulates the order sequence under consideration of e.g. delivery dates, availability of material taken from the ERP-system. The integrated backlog processing prioritizes orders to meet the planned delivery dates. The system schedules orders under consideration of restrictions such as conflicting targets (e.g. energy-efficiency vs. delivery time) or the limited availability of resources.

\footnotetext{
${ }^{1}$ Filtering algorithms can be a source of support by dividing the useable data collected from shop-floor sensors from noise and measurement errors.
} 


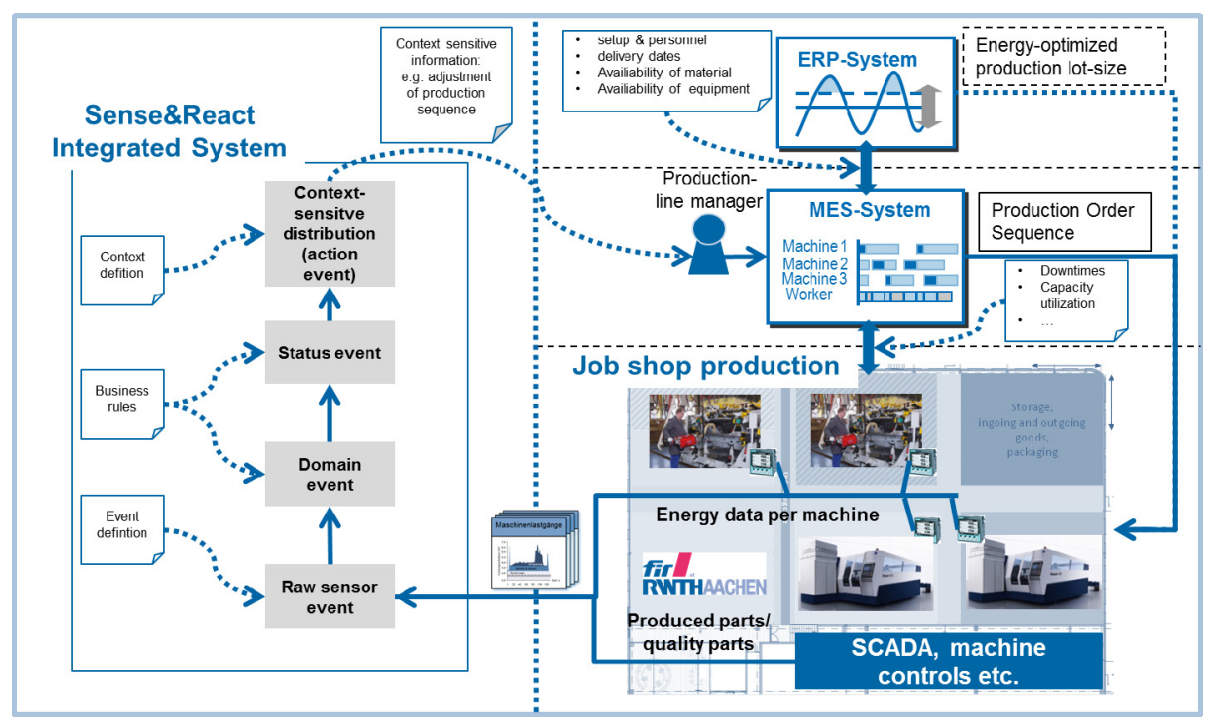

Fig. 2. Model of the energy-flexible Production sequencing

\section{$5 \quad$ Outlook and Further Research}

The control and exact prediction of the energy consumption of production processes under cost and purchasing aspects will become an important component of production planning and control in the near future. The main issues in this context are: Dispatching of energy-intensive orders in periods of lower energy costs and consideration of variable energy prices; short and middle term forecasting of energy consumption; support of seasonal purchase of energy; prevention of cost intensive overload scenarios (exceeding the contracted quantity of energy); directed manipulation of load curves; collection and consolidation of energy consumption data and continuous comparison with planned load curves.

The proposed concept provides a support for manufacturing industries to integrate energy relevant data information from sensors and in-process measurements into the planning systems. The use-case presented in this paper will be realized in the demonstration plant at the RWTH Aachen Campus Cluster Logistics which offers a real manufacturing plant for demonstration purposes. The demonstration plant is open to the public so interested companies can adapt the approach easily. The benefit for manufacturing companies will the ability to reduce energy costs. This can be done reducing total energy consumption as well as smoothing load profiles and avoiding peak load penalties. Additionally, the concept of CEP can easily be adapted to various kinds of optimization problems that require real-time information from the shop-floor. Further research has to focus on determining quantitative relations between production and energy-related targets for a given production setting e.g. a job shop production. Determining these interdependencies will help companies to act proactively upon the increasing uncertainty caused by energy-price and supply volatility by choosing the right energy-tariffs and adapting their production planning and control. 
Acknowledgement. The authors wish to thank the Sense\&React Consortium for their input and their support. The Sense\&React project is funded by the EU grant FP7-314350.

\section{References}

1. Bundesministerium für Wirtschaft und Technologie (BMWi). Energiekonzept für eine umweltschonende, zuverlässige und bezahlbare Energieversorgung. Report (September 28, 2010), http: / /www.bmu.de/fileadmin/bmu-import/files/pdfs / allgemein/application/pdf / energiekonzept_bundesregierung.pdf

2. IEA. Tracking Industrial, Energy Efficiency and $\mathrm{CO} 2$ Emissions, http: / / www. iea.org/textbase/nppdf/free/2007/ tracking_emissions.pdf

3. International Energy Agency, World Energy Outlook 2012, World energy outlook special report, International Energy Agency, Paris, France (2012)

4. Schönsleben, P., Bunse, K., Vodicka, M., Brüllhart, M., Ernst, F.O.: Integrating energy efficiency performance in production management - gap analysis between industrial needs and scientific literature. Journal of Cleaner Production 19, 667-679 (2011)

5. May, G., Taisch, M., Stahl, B., Sadr, V.: Toward Energy Efficient Manufacturing: A Study on Practices and Viewpoint of the Industry. In: Emmanouilidis, C., Taisch, M., Kiritsis, D. (eds.) Advances in Production Management Systems. IFIP AICT, vol. 397, pp. 1-8. Springer, Heidelberg (2013)

6. Sense\&React project homepage (March 19, 2013), http : / /www . sense-react . eu /

7. Kuhlmann, F., Amende, M.: EPC-Informationsservices (EPCIS) und Umsetzung im EPCShowcase. Konzept und Anwendung des EPCIS im EPCglobal-Netzwerk. Hg. v. GS1 Germany GmbH. GS1 Germany GmbH (2009) (in German)

8. Reinhart, G., Geiger, F., Karl, F., Wiedmann, M.: Handlungsfelder zur Realisierung energieeffizienter Produktionsplanung und -steuerung. ZWF 106(9), 596-600 (2011) (in German)

9. Erlach, K., Westkämper, E. (eds.): Energiewertstrom: Der Weg zur energieeffizienten Fabrik. Fraunhofer Verl. Stuttgart (2009) (in German)

10. Fleisch, E., Christ, O., Dierkes, M.: The Business Vision of the Internet of Things. In: Fleisch, E., Mattern, F. (Hrsg.) Das Internet der Dinge. Ubiquitous Computing und RFID in der Praxis: Visionen, Technologien, Anwendungen, Handlungsanleitungen, pp. 3-37. Springer, Berlin (2005) (in German)

11. Bottani, E., Rizzi, A.: Economical assessment of the impact of RFID technology and EPC system on the fast-moving consumer goods supply chain. International Journal of Production Economics 112(2), 548-569 (2008)

12. Zhou, S., Ling, W., Peng, Z.: An RFID-based remote monitoring system for enterprise internal production management. International Journal of Advanced Manufacturing Technology 33(7-8), 837-844 (2007)

13. Incel, O.D.: A survey on multi-channel communication in wireless sensor networks. Computer Networks 55(13), 3081-3099 (2011)

14. Chryssolouris, G.: Manufacturing Systems. Theory and Practice, 2nd edn. Springer, New York (2006)

15. Chalasani, S., Boppana, R.: Data Architectures for RFID Transactions. IEEE Transactions on Industrial Informatics 3(3), 246-257 (2007) 
16. Huang, G.Q., Zhang, Y.F., Chen, X., Newman, S.T.: RFID-enabled real-time Wireless Manufacturing for adaptive assembly planning and control. Journal of Intelligent Manufacturing 19(6), 701-713 (2008)

17. Fanian, A., Berenjkoub, M., Saidi, H., Gulliver, T.A.: A high performance and intrinsically secure key establishment protocol for wireless sensor networks. Computer Networks 55(8), 1849-1863 (2011)

18. Makris, S., Michalos, G., Chryssolouris, G.: A Pushlet-Based Wireless Information Environment for Mobile Operators in Human Based Assembly Lines. In: 7th International Conference on Digital Enterprise Technology (DET 2011), Athens, Greece, pp. 622-631 (2011)

19. Teizer, J., Vela, P.A.: Personnel tracking on construction sites using video cameras. Advanced Engineering Informatics 23(4), 452-462 (2009)

20. Feldmann, K., Slama, S.: Highly Flexible Assembly. Scope and Justification. Annals of the CIRP 50(2), 489-499 (2001)

21. Stankovski, S., Lazarevic, M., Ostojic, G., Cosic, I., Puric, R.: RFID technology in product/part tracking during the whole life cycle. Assembly Automation 29(4), 364-370 (2009)

22. Dunkel, J.: On Complex Event Processing for Sensor Networks. In: International Symposium on Autonomous Decentralized Systems, ISADS 2009, pp. 1-6 (2009)

23. Bruns, R., Dunkel, J.: Event-Driven Architecture. Softwarearchitektur für ereignisgesteuerte Geschäftsprozesse. Springer, Heidelberg (2010)

24. Michelson, B.M.: Event-Driven Architecture Overview. Event-Driven SOA is just part of the EDA story, Boston (2006)

25. Dunkel, J., Bruns, R., Pawlowski, O.: Complex Event Processing in Sensor-based Decision Support Systems. In: Nag, B. (Hg.) Intelligent Systems in Operations, pp. 64--79. IGI Global (2010)

26. Luckham, D.: The power of events. An introduction to complex event processing in distributed enterprise systems, 3rd print. Addison-Wesley, Boston (2005), Online verfügbar unter http: / /www.worldcat.org/oclc/255701022 